$$
\text { CONFGXI142 - B }
$$

DOE/MC/262 $28-93 / \mathrm{C} 0177$

Characterization of Uinta Basin Oil Sand Bitumens

Authors:

P.E. Rose

K. Bukka

M.D. Deo

F.V. Hanson

A.G. Oblad

Contractor:

University of Utah

3290 Merrill Engineering

Salt Lake City, Utah 84112

Contract Number:

DE-FC21-89MC26268

Conference Title:

1992 Eastern Oil Shale Symposium

Conference Location:

Lexington, Kentucky

Conference Dates:

November 13-15, 1992

Conference Sponsor:

Institute for Mining and Minerals Research
$\mathrm{DOE} / \mathrm{MC} / 26268--93 / \mathrm{C} 0177$

DE93 008868

1993

U $ن r 1$ 


\section{DISCLAIMER}

This report was prepared as an account of work sponsored by an agency of the United States Government. Neither the United States Government nor any agency thereof, nor any of their employees makes any warranty, express or implied, or assumes any legal liability or responsibility for the accuracy, completeness or usefulness of any information, apparatus, product, or process disclosed, or represents that its use would not infringe privately owned rights. Reference herein to any specific commercial product, process, or service by trade name, trademark, manufacturer, or otherwise, does not necessarily constitute or imply its endorsement, recommendation, or favoring by the United States Government or any agency thereof. The views and opinions of authors expressed herein do not necessarily state or reflect those of the United States Government or any agency thereof.

This report has been reproduced directly from the best available copy.

Available to DOE and DOE contractors from the Office of Scientific and Technical Information, P.O. Box 62, Oak Ridge, TN 37831; prices available from (615)576-8401, FTS 626-8401.

Available to the public from the National Technical Information Service, U.S. Depurtment of Commerce, 5285 Port Royal Rd., Springfield, VA 22161. 


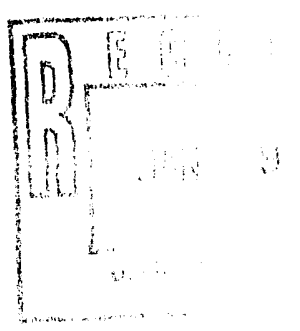

\title{
Characterization of Uinta Basin Oil Sand Bitumens
}

\author{
P.E. Rose, K. Bukka, M.D. Deo, F.V. Hanson, and A.G. Oblad \\ Department of Chemical and Fuels Engineering \\ University of Utah \\ Salt Lake City, Utah, $8+112$ \\ (801) $581-5.531$; F.AX: (801) $581-3344$
}

\begin{abstract}
Results of the analyses of the saturate and monoaromatic fractions of four Uinta Basin bitumens (southwest Whiterocks, northwest Whiterocks, Asphalt Ridge and Sunnyside) are presented in this paper. After separating the bitumen samples into several fractions using solvent extraction and elution chromatography, peak-by-peak analysis was performed on the saturate and monoaromatic fractions using GC-MIS. The saturated compounds were predominantly polycyclic naphthenes, while the monoaromatics were mostly naphthenoaromatics. Samples from all of the deposits contained a significant number of compounds in the carbon-number range $\mathrm{C}_{27}-\mathrm{C}_{30}$ due to the presence of steranes and hopanes. Carbon number and Z-number distributions were produced using sorting and quantitation procedures developed in this project. Although the four samples were believed to be of common origin and maturity, significant differences in carbon-number distributions and chemical-type distributions were shown to exist. Even two samples from the same deposit (Whiterocks) exhibited significant differences. Relative abundances of steranes and of hopanes with a carbon number greater than $\mathrm{C}_{30}$ were used as measures of the relative degree of biodegradation of the samples. It was found that biodegradation increased as follows: southwest Whiterocks < northwest Whiterocks < Asphalt Ridge < Sunnyside.
\end{abstract}




\section{Introduction}

Differences in composition between crude oils are generally attributed to one or more of the following: biodegradation, maturity, source, and migration. Biodegradation, in combination with water washing, is a process whereby lighter compounds, including alkanes, isoprenoids and alkylcyclohexanes, are bacterially degraded and removed from the reservoir oil. It is thought to be the major process whereby conventional oils are transformed into oil sand bitumen, and, therefore, a major contributor to compositional variation among deposits ${ }^{1}$. Evidence for the severe biodegradation of a Uintah Basin bitumen was presented by Reed ${ }^{2}$.

Thermal maturity can cause significant compositional variations between oils. And, while all of the Uinta Basin oil sand deposits are relatively immature, differences in maturity may be the cause of some of the compositional differences within the basin ${ }^{3,4}$.

Differences in source and the effects of migration are also known to effect composition. In the Uinta Basin, however, these effects are considered to be relatively minor, since these oils are believed to be of common origin and to have migrated relatively short distances from their source rock.

\section{Experimental Approach}

The oil sand samples chosen for this study were from the Whiterocks, Asphalt Ridge and Sunnyside deposits in the Uinta Basin, Utah. Samples from two locations in the Whiterocks deposit were collected ${ }^{5}$. These two samples will be referred to as northwest Whiterocks and southwest Whiterocks.

The bitumens were fractionated into their respective saturate and monoaromatic, polyaromatic, resin, and asphaltene fractions using the separation scheme shown in Figure $1^{6}$. The fraction containing the saturate and monoaromatic compounds was analyzed by gas chromatography-mass spectrometry (GC-MS). A J \& W Scientific DB-1 capillary column was used for all of the anaiyses. The $30 \mathrm{~m}$ long col-

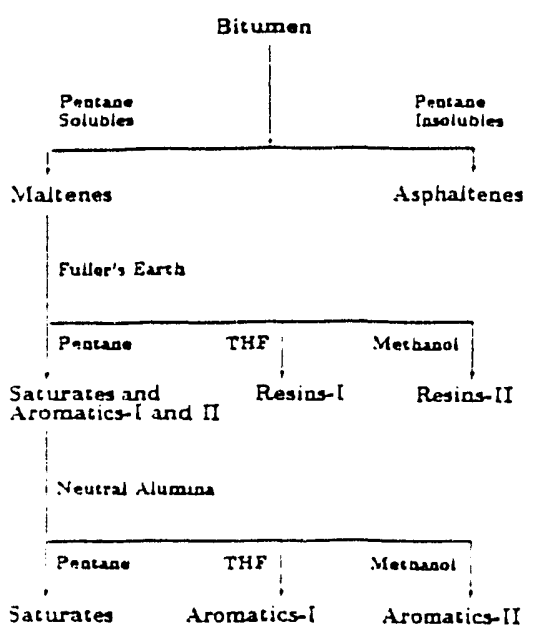

Figure 1: Bitumen Fractionation Scheme

umn was $0.25 \mathrm{~mm}$ in internal diameter and was coated with a 0.25 micron film of a polysiloxane bonded phase. The samples were coated onto a Curie-point wire and vaporized in to the column. The initial temperature of the column was $30^{\circ} \mathrm{C}$. It was heated to a final temperature of $350^{\circ} \mathrm{C}$ at the rate of $3{ }^{\circ} \mathrm{C}$ per minute. The mass spectrometer was used in an electronimpact mode and an ion-trap detector was used to obtain spectra of the eluting compounds.

\section{Structural Analysis}

Compound identification was accomplished by analyzing the total-ion chromatogram peak by peak using Finnegan's Ion Trap Detector System (ITDS) software ${ }^{7}$. Individualcompound spectra and mass-spectral libraries were used to identify the peaks in the samples. Each sample consisted of about $80-100$ compounds. It was assumed that the response factors for each compound were equal and that area percentage was equivalent to weight percentage. The weight-percent information was stored in a data file along with the scan number and identity of each compound type. The molecular weight, the number of carbon atoms per molecule, the number of aromatic and nonaromatic rings per molecule, and the $\mathrm{Z}$ number were also recorded. The $Z$ number is 
defined as the value of $Z$ in the general hydrocarbon formula $C_{n} H_{2 n+Z}$.

While the ITDS software was very useful in analyzing individual compound types, it was inadequate for categorizing and sorting compounds according to carbon number, molecular weight, or $\mathrm{Z}$ number. A computer program was written in FORTRAN to process such information. The program determines relative abundance according to carbon number, molecular weight, or compound type (i.e., $Z$ number). It can also be used to determine relative abundance vs. carbon number for a particular $Z$ number. In the fractionation process described above. saturated hydrocarbons eluted simultaneously with alkylbenzenes and monoaromatic naphthenoaromatics (jointly classified as monoaromatics for convenience). Using this computer code, saturated hydrocarbons were separated from monoaromatics by normalizing separately for the total peak area in each category.

\section{Carbon-Number Distributions}

A plot of cumulative relative abundance vs. carbon number is shown in Figure 2 for samples of saturated hydrocarbons from the three deposits. Over $60 \%$ of saturates from Asphalt Ridge are between $\mathrm{C}_{11}$ and $\mathrm{C}_{15}$. And over $30 \%$ fall between $\mathrm{C}_{27}$ and $\mathrm{C}_{30}$. The southwest Whiterocks sample, however, exhibits a much different distribution with only about $15 \%$ of its saturates below $\mathrm{C}_{26}$ and about $45 \%$ between $\mathrm{C}_{28}$ and $\mathrm{C}_{30}$. The northwest Whiterocks and Sunnyside samples show strikingly similar curves, with carbon-number distributions mostly between those of the Asphalt Ridge and southwest Whiterocks saturate samples.

A plot of cumulative relative abundance vs. carbon number is shown in Figure 3 for the monoaromatic fracion of each of the four samples. The carbon-number distributions for the monoaromatic fractions show similar trends to those of the saturate fraction. The Asphalt Ridge sample has the lowest average carbon number, while the southwest Whiterocks sample has the highest average carbon

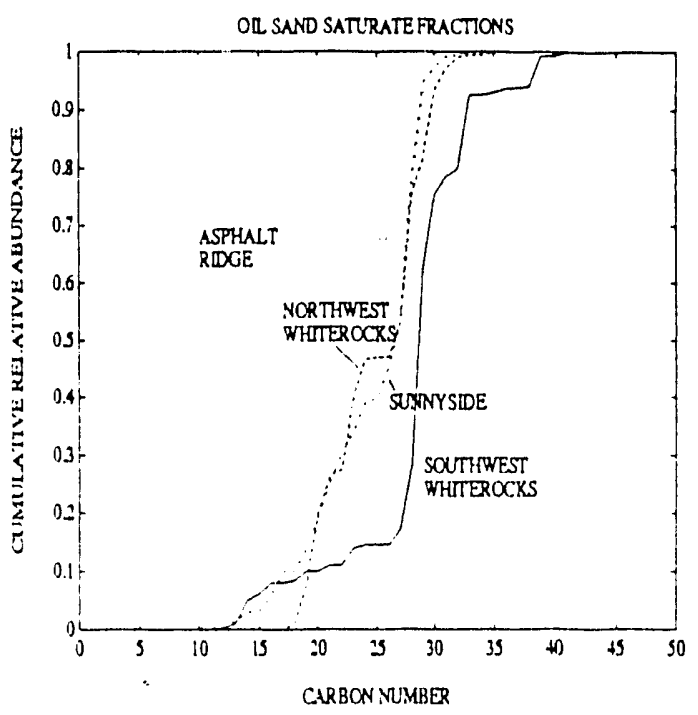

Figure 2: Carbon Number Distribution for Saturate Fractions

number. And, as with the saturate fractions, the carbon-number distributions for the northwest Whiterocks and Sunnyside monoaromatics lie roughly between those of the other two monoaromatic fractions.

\section{Z-Number Distributions}

In addition to analysis by carbon-number distributions, Partition can be used to plot relative abundance vs. $\mathrm{Z}$ number, where the $\mathrm{Z}$ number is defined according to the general hydrocarbon formula, $\mathrm{C}_{n} \mathrm{H}_{2 n+Z}$. For the saturate fractions, the $Z$ number can have the values of $0,-2,-4,-6$, or -8 , representing compounds having $1,2,3,4$, and 5 rings, respectively. For the monoaromatic fractions, the $\mathrm{Z}$ number can have the values of $-6,-8,-10$, -12 , or -14 , representing naphthenoaromatics having $1,2,3,4$, and 5 rings, respectively. Thus, the $\mathrm{Z}$ number is a measure of the hydrogen deficiency. As the number of rings increases, the $\mathrm{Z}$ number becomes more negative, and the hydrogen-to-carbon ratio decreases. It is important to note that only gross structural information such as number of rings, carbon 


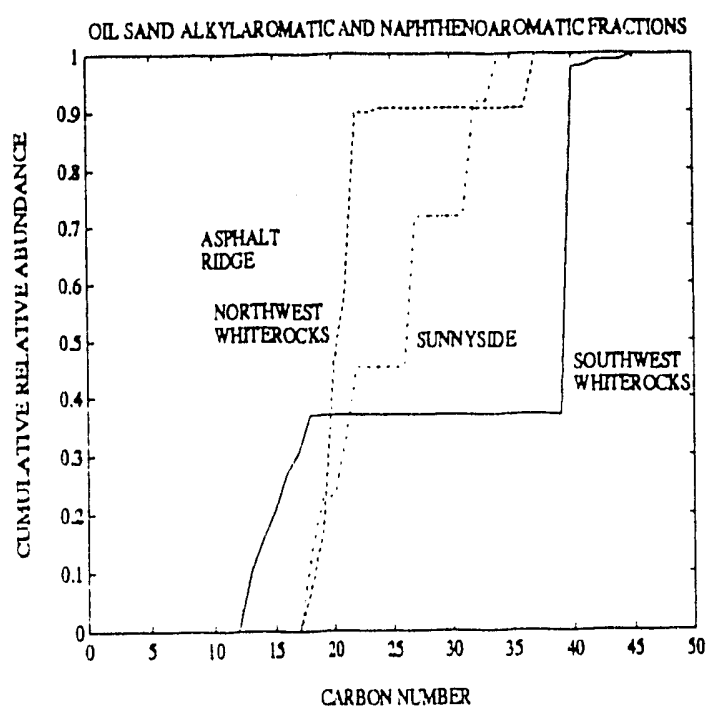

Figure 3: Carbon Number Distribution for Monoaromatic Fractions

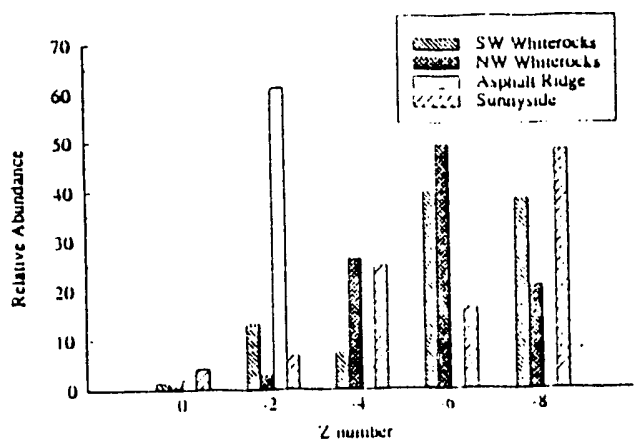

Figure 4: Z Number Distribution for Saturates

number, molecular weight, and $\mathrm{Z}$ number was determined in this analysis. Structural detail such as the position of side chains, the length of particular side chains, and stereochemistry was not determined.

The relative abundance vs. $Z$ number for the saturate fractions of each sample is plotted in Figure 4. It is evident that the alkylcyclohexanes are in very lo:v concentration for all of the samples. And while the bicyclics are in relatively low concentration for the Whiterocks and Sunnyside samples, they represent over $60 \%$ of the Asphalt Ridge sample.

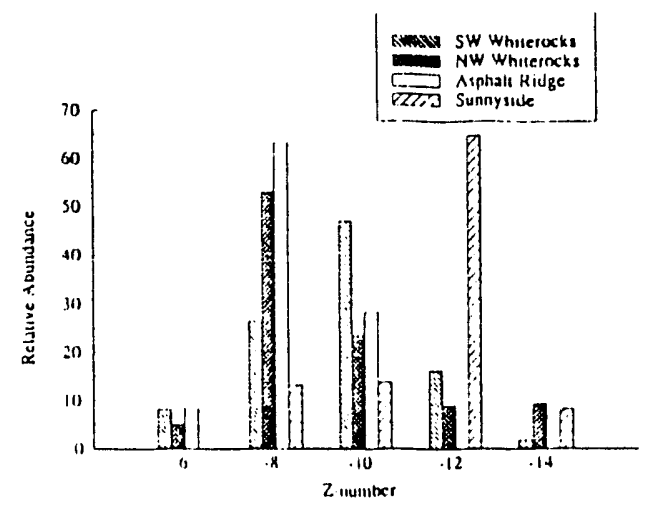

Figure 5: Z Number Distribution for Monoaromatics

The Z-number distribution for the monoaromatic fractions of each sample is shown in Fig. ure 5. It is evident that both the alkylbenzenes and the monoaromatized pentacyclics are in relatively low concentration. As with the saturate fractions, the 2 -ring $(Z=-8)$ compounds have the highest relative abundance for the Asphalt Ridge sample. The Sunnyside sample shows the domination of 4 -ring $(Z=-12)$ compounds.

\section{Biodegradation}

The compound types found in the saturate and monoaromatic fractions are in a class of chemicals called "biomarkers". As such, they are used to make determinations about the maturity, source, migration, and degree of biodegradation of oil. In general, oil sand bitumens are moderately-to-heavily biodegraded oils, meaning that they are partlyto-completely devoid of n-alkanes, isoprenoids, and alkylcyclohexanes ${ }^{8,9,10}$. The analyses indicated that, among the saturate samples, nalkanes and isoprenoids were undetected, while alkylcyclohexanes were present in only trace concentrations. This implies, of course, that the bitumens are devoid of these compound types, since, if they were present, they would have eluted with the saturates.

Since n-alkanes, isoprenoids, and alkylcyclohexanes are absent in heavily biodegraded oils, it is necessary to examine the relative concentrations of compounds that are increas- 
ingly more resistant to biodegradation in order to determine the relative degree of biodegradation of bitumens. After the disappearance of n-alkanes, isoprenoids, and alkylcyclohexanes, the next most likely compounds to be biodegraded are steranes ${ }^{9,10}$. Therefore, as biodegradation increases, the relative abundance of steranes decreases. A similar measure of biodegradation in heavily biodegraded oils is the ratio of $\mathrm{C}_{30}$ thopanes to all of the hopanes within a sample ${ }^{11,12}$. The hopanes with long side chains (i.e., high carbon numbers) are biodegraded preferentially and the hopane $\mathrm{C}_{30}+$ fraction decreases as the degree of biodegradation increases. Table 1 lists the relative abundance of steranes and the $\mathrm{C}_{30+}$ fraction for each of the four samples. showing that, by both of these measures. the degree of biodegradation progresses steadily from southwest Whiterocks to Sunnyside.

Table 1

Relative Degree of Biodegradation of Uinta Basin Bitumens

\begin{tabular}{||c|c|c||}
\hline \hline Deposit & $\begin{array}{c}\text { Sterane } \\
\text { Fraction }\end{array}$ & $\begin{array}{c}\text { Hopane } \\
C_{30} \text { Fraction }\end{array}$ \\
\hline \hline $\begin{array}{c}\text { Southwest } \\
\text { Whiterocks }\end{array}$ & 0.139 & 0.379 \\
$\begin{array}{c}\text { Northwest } \\
\text { Whiterocks }\end{array}$ & 0.112 & 0.259 \\
Asphalt Ridge & 0.054 & 0.133 \\
Sunnyside & 0.029 & 0.013 \\
\hline
\end{tabular}

\section{Conclusions}

Carbon-number and Z-number distributions were determined for the saturate and monoaromatic fractions from 4 samples representing 3 oil sand deposits in the Uinta Basin, Utah. A wide inter-deposit variation in compound type was observed for both the saturates and monoaromatics. Likewise, a significant variation in compound-type distribution and carbon-number distribution was evidenced for 2 samples from the Whiterocks deposit. These differences in distribution might be due, in part, to the relative degree of biodegradation of each sample. Two biodegradation parameters, the sterane fraction and the hopane $\mathrm{C}_{30+}$ fraction. suggest an increase in the relative degree of biodegradation as follows: southwest Whiterocks < northwest Whiterocks < Asphalt Ridge < Sunnyside.

\section{Acknowledgements}

The authors acknowledge the financial support of the C.S. Department of Energy through the Laramie Projects Office of the Morgantown Energy Technology Center and the Mineral Leasing Fund from the College of Mines and Earth Sciences at the University of Utah, and the Laramie Projects Office of the Morgantown Energy Technology Center at the Department of Energy. P.E. Rose acknowledges the support provided by the Dougan Fellowship from the Department of Chemical and Fuels Engineering.

\section{References}

1. Lin, L.H., Michael, G.E., Kovachev, G., Zhu, H., Philp, R.P., Lewis, C.A., "Biodegradation of Tar-Sand Bitumens from the Ardmore and Anadarko Basins, Carter County, Oklahoma", Org. Geochem., 14(5), 511-523, 1989.

2. Reed, W.E., "Molecular Compositions of Weathered Petroleum and Comparison with Its Possible Source", Geochem. Cos. Acta, 41, 237-24i, 1977.

3. Curiale J.A., "Origin of Solid Bitumens, with Emphasis on Biological Marker Results", Org. Geochem., 10, 559-580, 1986.

4. Tissot, B., Deroo, G., "Geochemical Study of the Uinta Basin: Formation of Petroleum from the Green River Forma- 
tion", Geochem. Cos. Acta, 42, 1469148.5, 1978.

5. Longstaff, D.C.. Deo, M.D., Hanson, F.V., Oblad, A.G., Tsai, C.H., "Hydrotreating the Bitumen-derived Hydrocarbon Liquid Produced in a Fluidized-bed Pyrolysis Reactor", Fuel, 71, 1407-1413, 1992.

6. Ion Trap Detector Operation Manual, P/N 94011-98025 Revision D, Finnegan MAT, 35.5 River Oaks Parkway, San Jose, CA. 1986.

7. Volkman J.K.. Alexander, R., Kagi, R.I.. Rowland, S.J.. Sheppard, P.N., "Biodegradation of Aromatic Hydrocarbons in Crude Oils from the Barrow Sub-basin of Western Australia", Org. Geochem., 6, 619-632. 1984.

8. Connan. J., "Biodegradation of Crude Oils in Reservoirs", Adv. Pet. Geochem., $1,299-335,1984$.

9. Brooks, P.W.. Fowler. M.G., Macqueen, R.W.. "Biological Marker and Conventional Organic Geochemistry of Oil Sands/Heavy Oils, Western Canada Basin Org. Geochem., 12(6), 519-538, 1988.

10. Goodwin N.S., Park, P.J.D., Rawlinson, A.P., "Crude Oil Biodegradation under Simulated and Natural Conditions", Adv. Org. Geochem, 650-658, 1983.

11. Michael, G.E., Lin, L.H., Philp, R.P., Lewis, C.A., Jones, P.J., "Biodegradation of Tar-sand Bitumens from the Ardmore/Anadarko Basins, Oklahoma-II. Correlation of Oils, Tar Sands and Source Rocks", Org. Geochem., 14(6), 619-633, 1989. 

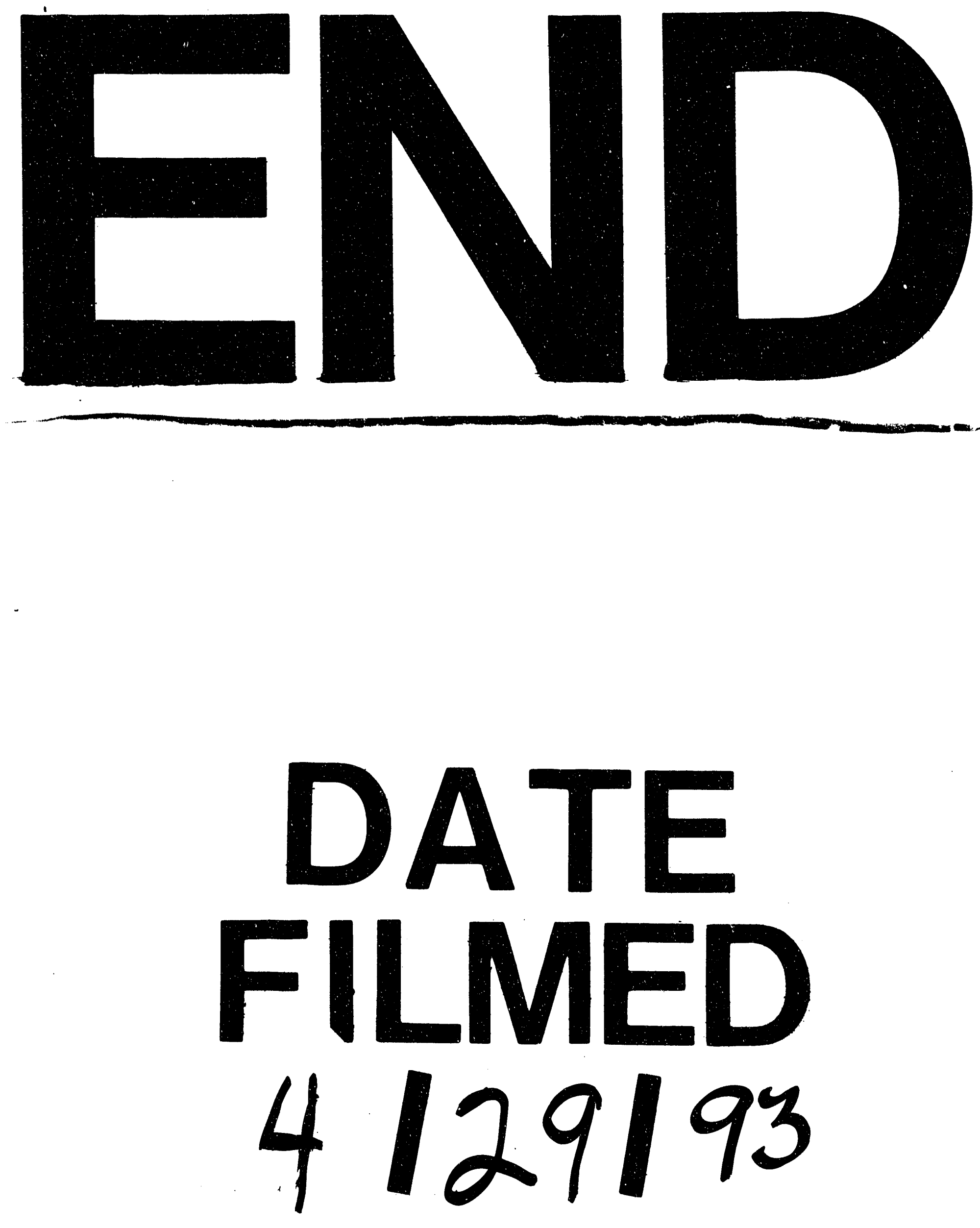
